\title{
THE COMPRESSION AND UPLIFT BEARING CAPACITIES OF HELICAL PILES IN COHESIONLESS SOIL
}

\author{
Hamdy H.A. Abdel-Rahim , Yehia Kamal Taha and Walla El din El sharif Mohamed
}

Staff in Civil Engineering Department, Faculty of Engineering, Assiut University

Received 5 October 2013; accepted 29 October 2013

\begin{abstract}
Helical piles have been used widely in engineering application . They can be used to provide structural stability against axial compression, uplift and lateral forces. . In recent years, helical pile foundations have become more widely used in many countries. There are few studies about helical piles, for this reason the aim of the present paper is to study how to improve the prevision of the compression and uplift capacities of helical piles, and study the effect of embedded depth and helical area of helical piles in sand soil on the compression and uplift bearing capacities.

Studies of helical piles with different areas of helices provided are in continuation. Compression and uplift loads were applied at different height within the soil. The embedment length of screw anchor piles was also varied to study the behavior of helical piles under compression and uplift loads.

Various size and numbers of helices have been used in the laboratory tests with diameters $5,6.7$, 8.2 and $10 \mathrm{~cm}$ with varying lengths. The embedment ratios for each ,D/d are $1,2,3,4,5,6$ and 7 .

An experimental setup instrumented to allow the measurement of the compression and pullout loads which affect on the helical pile installed into prepared layers of sand until failure.

The results show that the compression and pullout resistance of helical anchors is strongly affected by the area and composition of helical plates welded to the pile steel shaft. The compression and uplift loads are increased with increasing of the embedment ratios, D / $\mathrm{d}$ and helix diameter, $\mathrm{d}$. In addition to some other useful results are indicated in this paper.
\end{abstract}

Keywords: helical pile, sand, soil, compression load, uplift load, experimental work.

\section{Introduction}

Helical piles are galvanized steel shafts with several high-strength helices welded on; securely coupled sectional segments are rotated into the ground at a desired angle providing end-bearing vertical or lateral foundation support reaching competent soil or bedrock Helical foundation systems are ideal foundation alternative for weak soils, expansive soils, high ground-water projects, hillsides, creeksides, bay mud Helical piles have been widely used in engineering applications to provide structural stability against axial compression, uplift tension, overturning moment and lateral force.

1-Asst. Prof. of theory of Structure. Engineering, Civil Engineering Department,

2- Lect,. of Soil Mech. And Found. Engineering, Civil Engineering Department,

3-Civil Eng. Asst Researcher, Engineering, Civil Engineering Department,

The fast installation, the instant use, and other advantages over the traditional pile system have widened the use of screw anchor piles as deep foundation for various structures.

Helical screw piles have many advantages. For example, the installation cost is relatively low, with a typical installation requiring only two people per crew. They are fast and easy to install. A $5 \mathrm{~m}$ pile installed into Lake Edmonton clay requires approximately 20 minutes. In addition. they can be easily transported, removed and reused, they allow immediate

\footnotetext{
* Corresponding author.

E-mail address: hamdy010@yahoo.com
} 
Hamdy H.A. Abdel-Rahim et al., The compression and uplift bearing capacities of helical piles in cohesionless soil, pp. 2055 - 2064

loading once installed, they can be installed under variable weather and site condition; and most importantly, relatively large capacity can be achieved using these screw piles.

A reference made on the use of screw piles for Maplin sand lighthouse was referred to by Little [1]. This word has been followed up by several researchs. Wilson [2] has done a very good work on the bearing capacity of screw piles. Meyerhof [3] suggested the "theory of plasticity for determining the bearing capacity of screw piles. Skempton [4] also suggested formulation to predict the capacity of the screw pile and reported field test results supported the formulations. For a cohesionless soil the ultimate compression capacity of the helical pier using a cylindrical shearing method as proposed by Mitsch and Clemence [5] is:

$\mathrm{Qu}=$ Qhelix + Qbearing + Qshaft

Qhelix = 0.5. $\pi$.Da $\cdot \gamma^{\prime} \cdot\left(\mathrm{H}^{2}{ }_{3}-\mathrm{H}^{2}{ }_{1}\right) \cdot \mathrm{K}_{\mathrm{S}} \cdot \tan \phi$

Qbearing $=\gamma$ '. $\mathrm{H} \cdot \mathrm{A}_{\mathrm{h}} \cdot \mathrm{Nq}$

Qshaft $=0.5 \rho_{\mathrm{s}} \cdot \mathrm{H}_{\text {eff }}^{2} \cdot \gamma^{\prime} \cdot \mathrm{Ks} \cdot \tan \phi$

Where: $\mathrm{Qu}=$ Ultimate compression capacity, $(\mathrm{KN})$

$\gamma^{\prime}=$ Effective unit weight of soil $\left(\mathrm{KN} / \mathrm{m}^{3}\right)$

$\mathrm{Ks}=$ Coefficient of lateral earth pressure in compression load.

$\phi=$ Soil angle of internal friction, degree

$\mathrm{A}_{\mathrm{h}}=$ Area of bottom helix, $\mathrm{m}^{2}$

$\mathrm{Nq}=$ Dimensionless bearing capacity factor

$\mathrm{Da}=$ Average helix diameter, $(\mathrm{m})$

$\mathrm{H}=$ The embedment depth of pile, (m)

$\mathrm{D}_{1}=$ Diameter of top helix, (m)

$\mathrm{H}_{\text {eff }}=$ Effective shaft length, (m)

$\mathrm{H}_{1}=$ Depth of top helix, (m)

$\mathrm{H}_{3}=$ Depth of helix, (m)

$\rho_{\mathrm{s}}=$ The perimeter of the helix pier shaft, (m)

The bearing capacity of vertically oriented helix piers is given by Mitsch and Clemence [5], Ghaly and Clemence [6], A.B. chance [7], Hot and Clemence [8]:

$\mathrm{Qu}=(2 \pi \cdot \mathrm{R} . \mathrm{L}) \mathrm{s}+\left(\pi \cdot \mathrm{R}_{\mathrm{B}}^{2} \cdot\right) \mathrm{q}$

Where $\mathrm{R}$ is average blade radius, $\mathrm{R}_{\mathrm{B}}$ is bottom blade radius, $\mathrm{L}$ is total spacing between all blades, $\mathrm{s}$ and $\mathrm{q}$ in the equation are for ultimate bearing capacity determination.

The helix capacity is determined by calculating the unit bearing capacity of the soil and applying it to the individual helix areas as the following equation:

$\mathrm{Q}_{\mathrm{h}}=\mathrm{A}_{\mathrm{h}}(9 \mathrm{c}+\mathrm{q} \cdot \mathrm{Nq})$

Where:

$\mathrm{Q}_{\mathrm{h}}=$ individual helix bearing capacity

$\mathrm{A}_{\mathrm{h}}=$ Projected helix area

$\mathrm{c}=$ Soil cohesion

$\mathrm{q}=$ effective overburden pressure

$\mathrm{Nq}=$ Bearing capacity factor

Sharif [9], studied the behavior of helical pier in sand and he found that for any size of helical piers installed in the sand with various embedded depths the capacities of helical

Journal of Engineering Sciences, Assiut University, Faculty of Engineering, Vol. 41, No. 6, November, 2013, E-mail address: jes@aun.edu.eg 
Hamdy H.A. Abdel-Rahim et al., The compression and uplift bearing capacities of helical piles in cohesionless soil, pp. 2055 - 2064

pier in dense sand, $\mathrm{Pd}$ is greater than that in loose sand, and $\mathrm{P}_{\mathrm{L}}$. The relation can be formalized as: $\mathbf{P d}=\mathbf{1 . 6} \mathbf{P L}$

Ghaly [10], studied the derivability and pullout resistance of helical units in saturated sand .He concluded that the helical units installed in submerged sands encounter less resistance than those installed in dry sand with comparable characteristics the ultimate uplift capacity can be estimated as the sum of the effective weight of the soil located in the failure zone and the shearing resistance developed along the failure surface. However, the difficulties of estimating the uplift capacity of an anchor lie in the difficulties of predicting the geometry of the failure zone.

Das [11] has summarized some of the early theories for predicting the uplift capacity of shallow anchor in sand as shown in Figure [1]

Parr and Vanner [12] indicated that the friction cylinder method works in cases where the strength of the soi 1 medium can be effectively mobilized. The method might only apply to backfilled footing but not to flared-out footing.

Das [11] indicated that Balla's theory is in good agreement for the uplift capacity of anchors embedded in dense sand at an embedment ratio of $H / D \leq 5$. However, for anchors located in loose to medium sand and with embedment ratio $H / D>5$, the theory overestimates the net ultimate uplift capacity. The main reason for this overestimation is that the failure surface does not extend to the ground surface in these cases.

Mitsch and Clemence [13] proposed a semi empirical solution to predict the ultimate uplift capacity of helical anchor in sand. They introduced values for coefficient of lateral earth pressure as a function of H/D ratio and relative density. Their values were 30 to $40 \%$ reduction compared with those proposed by Meyerhof and Adams [14]. They indicated that this reduction caused by the shearing disturbance of the soil during anchor installation. Clemence and Pepe[15] studied the effect of installation and pullout of anchors on the lateral stress in the sand layer. The values of lateral earth pressure measured before and after the installation of anchor, at the failure of anchor and continuously during the application of the uplift loads. From the test, they indicated that the installation of helical anchors in dry sand causes an increase in lateral earth pressure around the anchor and the pressure was significantly increased in dense sand.

They concluded that the increase of lateral earth pressure depends on the relative density of sand and the embedment ratio (H/D).

Based on the result from a laboratory test, Ghaly and Hanna [16] indicated that there are three components mainly contribute to the uplift capacity of shallow anchor, which are the self weight of anchor, weight of sand within the failure surface and the friction along the failure surface.

From the experiment result, a theoretical model was developed by using the limit equilibrium technique and Kotter's differential equation. In this model, they assumed the failure surface in log-spiral shape. In their model, they have reduced the complexity of model by developing the weight and shear factors for shallow and deep anchors. These factors presented in graph that plotted with the friction angle and embedment depth ratio.

Journal of Engineering Sciences, Assiut University, Faculty of Engineering, Vol. 41, No. 6, November, 2013, E-mail address: jes@aun.edu.eg 
Hamdy H.A. Abdel-Rahim et al., The compression and uplift bearing capacities of helical piles in cohesionless soil, pp. 2055 - 2064

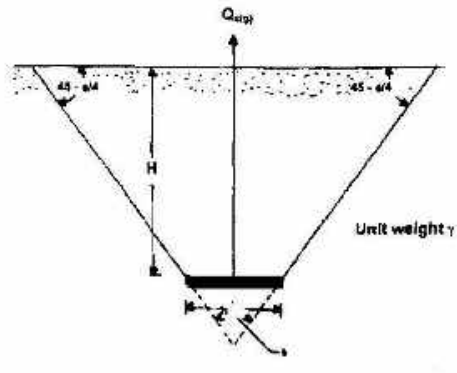

a) Soil Cone Method

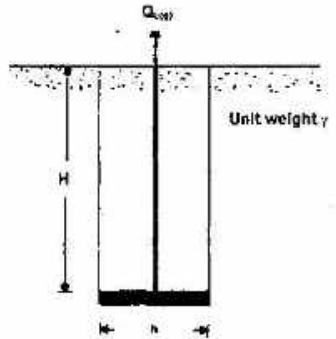

b) Friction Cylinder Method

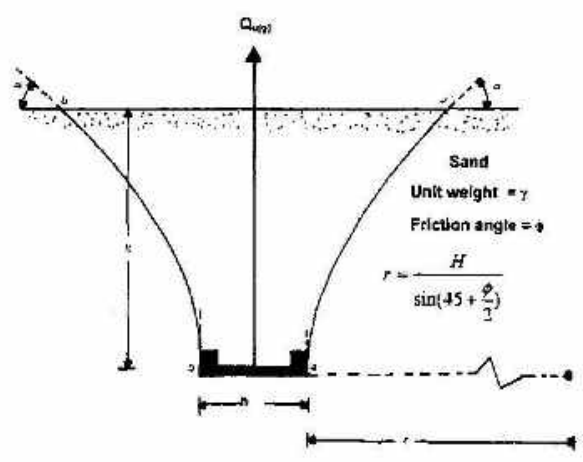

C) Balla's Theory for Shallow Circular Anchor

Figure 2.25: Previous Uplift Bearing Capacity Theories (after Das, 1990)

Fig.1. Pervious uplift bearing capacity theories (after Das, [11])

\section{Experimental Work}

\section{1. $\quad$ Material used}

The soil used in the tests was Medium to Fine sand soil.

The grain size distribution of this soil is indicated 65\% Medium sand and 35\% Fine sand.

The properties of the sand are :

The sand Specific gravity is 2.62 ,

Maximum dry density is $1.89 \mathrm{t} / \mathrm{m}^{3}$,

Minimum dry density is $1.41 \mathrm{t} / \mathrm{m} 3$, and

The angle of internal friction for sand particles is $34^{\circ}$

Journal of Engineering Sciences, Assiut University, Faculty of Engineering, Vol. 41, No. 6, November, 2013,E-mail address: jes@aun.edu.eg 
Hamdy H.A. Abdel-Rahim et al., The compression and uplift bearing capacities of helical piles in cohesionless soil, pp. 2055 - 2064

2.2. Model tests

\subsubsection{The model of helix (figure 2)}

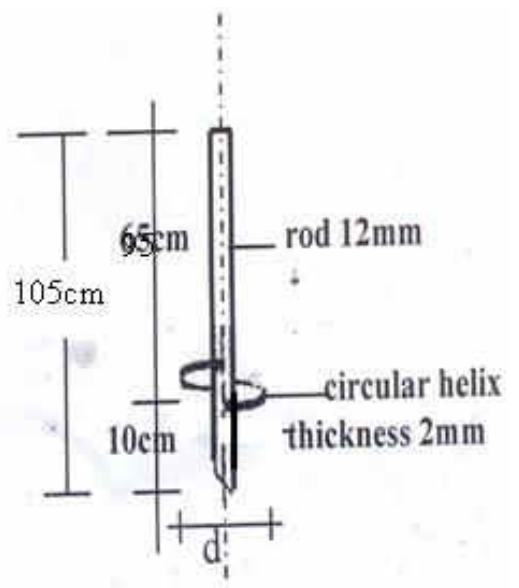

Fig. 2. Helix Pile Foundation Model .

\section{The model of helix : (figure(1)}

Four model helices made from mild steel rod welded with mild steel helical plate were investigated. The rod is circular section with diameter equal $12.7 \mathrm{~mm}$ and length is 100 $\mathrm{cm}$. The diameters of helix are 5,6.7, 8.2, and $10 \mathrm{~cm}$ and these have thickness $2.5 \mathrm{~mm}$. (The laboratory models were scaled with the field prototype as percentage (1:3) respe ctively.

\subsubsection{The test tank: (figure(3))}

A steel tank with dimension $1.75 \times 1.75 \times 2 \mathrm{~m}$ was employed in the tests. A rigid frame mounted on the box provided reaction. The compression and pullout loads were applied by a manually operated hydraulic jack connected to a proving ring for measuring the loads, and two dial gauges were used to measure the downward and upward movements of helix. The jack is positioned as shown in figure (3) and enough care has been taken to assure that there is no eccentricity in loading.

\subsubsection{Testing program and procedure}

A homogeneous deposit was obtained by filling sand gradually into the tank. The dry density of the sand was $1.70 \mathrm{t} / \mathrm{m}^{3}$. The density of the sand was controlled to remain it constant in the tank by placing the sand in the tank using a funnel such that its height was constant above the sand top level during the falling process. After the sand has been formed, the helical pile has been slowly screwed into the soil with sufficient downward force by applying torque to the upper end of the shaft until the final installation depth was reached. The tests were conducted at a depth of soil with embedment ratio, D/d equals one. The test load was applied on a pile head by means of a hydraulic jack. The compression or uplift loads and movements were recorded until failure by using proving ring and dial gauges.

Journal of Engineering Sciences, Assiut University, Faculty of Engineering, Vol. 41, No. 6, November, 2013, E-mail address: jes@aun.edu.eg 
Hamdy H.A. Abdel-Rahim et al., The compression and uplift bearing capacities of helical piles in cohesionless soil, pp. 2055 - 2064

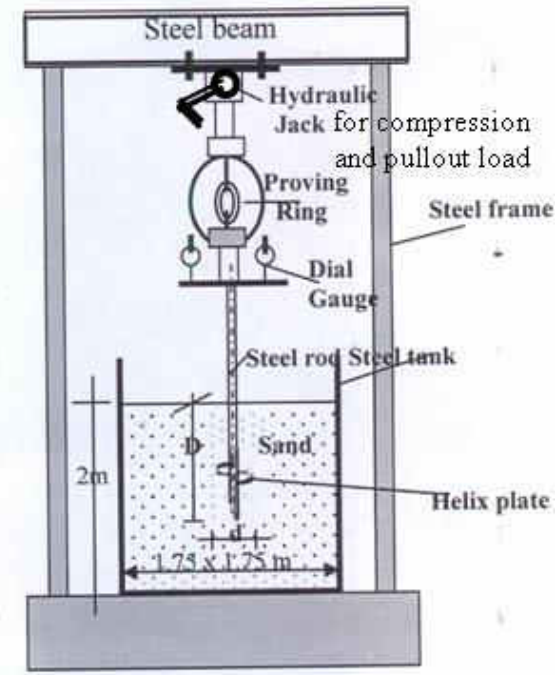

Fig. 3. Experimental set- up for compression and uplift t ests.

Tests were conducted for various helix diameters $5,6.7,8.2$ and $10 \mathrm{~cm}$.

Under the same states of soil the tests were repeated with increasing embedment ratios, $\mathrm{D} / \mathrm{d}$ to $2,3,4,5,6$ and 7 .

The tests were repeated with changing the diameter of helix with the same type and state of soil. For each model test, the soil was removed from the tank and was replaced by the required depth and density.

Tests were replaced three times for each case of helical pile and the results reported herein are the average of three tests.

\section{Results and Dissections}

The behavior of the helical pile can better be assessed with the help of results obtained from compression and uplift load tests.

Typical compression loads of helical,(Pc),kg against embedment ratio, D/d equal $1,2,3,4,5,6$ and 7 for helix diameters, $\mathrm{d}$ equal 5, 6.7, 8.2 and $10 \mathrm{~cm}$ in sand are shown in figure(4) .It can be noticed the compression loads increase with increasing the embedment ratio, $\mathrm{D} / \mathrm{d}$.The relationships can be represented as follows:

$\mathrm{Pc}=25.9(\mathrm{D} / \mathrm{d})+27.08 \quad-----------$ For $\mathrm{d}=5 \mathrm{~cm}$
$\mathrm{Pc}=42.1(\mathrm{D} / \mathrm{d})+68.7 \quad----------$ For $\mathrm{d}=6.7 \mathrm{~cm}$
$\mathrm{Pc}=55.6(\mathrm{D} / \mathrm{d})+99.1 \quad------------$ For $\mathrm{d}=8.2 \mathrm{~cm}$
$\mathrm{Pc}=65.1(\mathrm{D} / \mathrm{d})+149.2 \quad----------$ For $\mathrm{d}=10 \mathrm{~cm}$

Journal of Engineering Sciences, Assiut University, Faculty of Engineering, Vol. 41, No. 6, November, 2013, E-mail address: jes@aun.edu.eg 
Hamdy H.A. Abdel-Rahim et al., The compression and uplift bearing capacities of helical piles in cohesionless soil, pp. 2055 - 2064

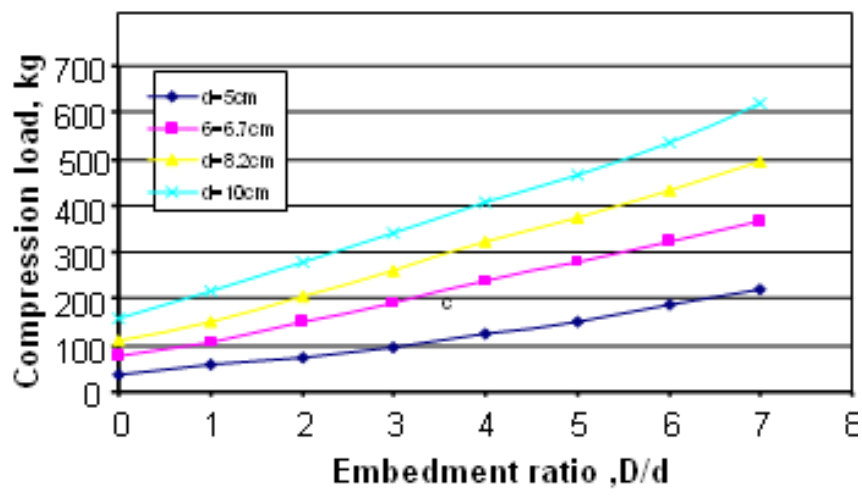

Fig.4. Relations between compression load,kg, $\mathrm{kg}$ and embedment ratio,D/d

Figure(5) shows the relationships between the compression loads( $\mathrm{Pc}), \mathrm{kg}$ and the diameter of helices,(d), $\mathrm{cm}$ in sand for the embedment ratios, $\mathrm{R}$ equal $0,1,2,3,4,5,6$ and 7 . It can be noticed that the compression loads increase with increasing of diameter of helix and the relations can be represented as follows:

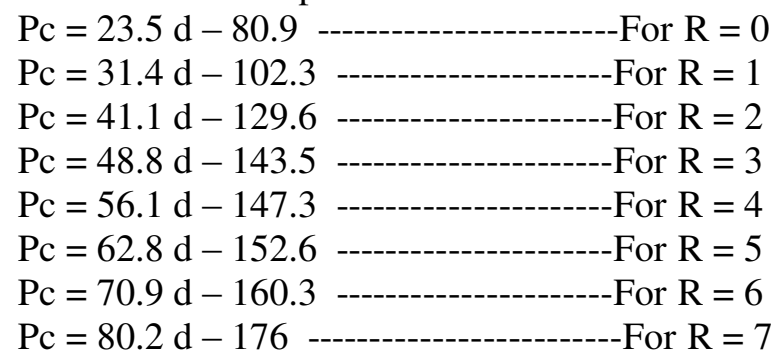

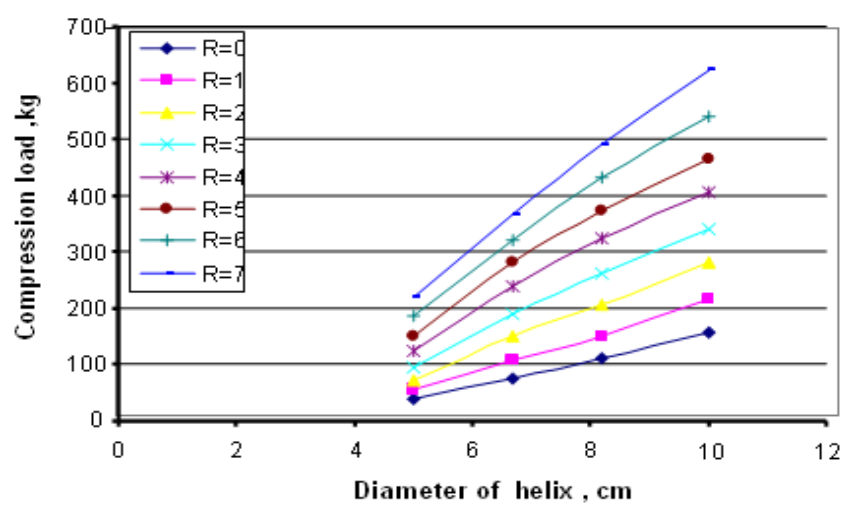

Fig. 5. Relation between compression load,kg and diameter of helix(d), cm with different emedment ratios, $\mathrm{D} / \mathrm{d}$.

Typical uplift loads of helical,(Pu),kg against embedment ratio, D/d equal 1,2,3,4,5,6 and 7 for helix diameters, d equal 5, 6.7, 8.2 and $10 \mathrm{~cm}$ in sand are shown in figure (6). The uplift loads increase with increasing the embedment ratio, $\mathrm{D} / \mathrm{d}$.The relationships can be represented as follows:

Journal of Engineering Sciences, Assiut University, Faculty of Engineering, Vol. 41, No. 6, November, 2013, E-mail address: jes@aun.edu.eg 
2062

Hamdy H.A. Abdel-Rahim et al., The compression and uplift bearing capacities of helical piles in cohesionless soil, pp. 2055 - 2064

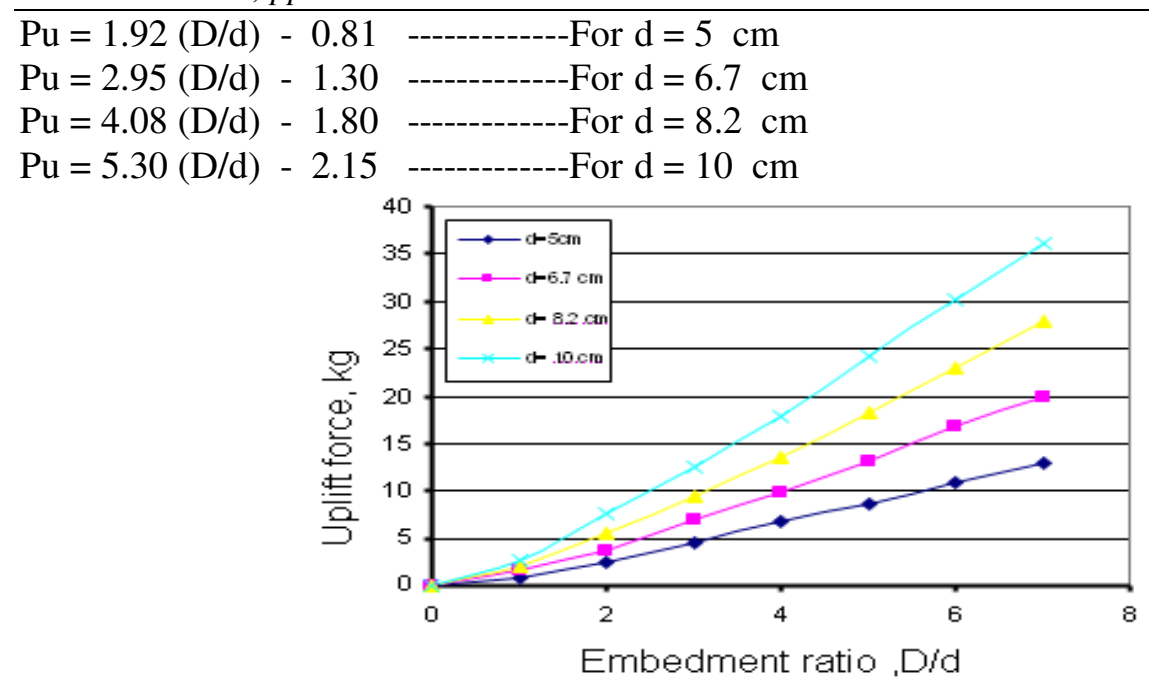

Fig. 6. Relations between uplift forc, $\mathrm{kg}$ and Embedment ratio, D/d .

Fig.(7) shows the relationships between the uplift loads $(\mathrm{Pu}), \mathrm{kg}$ and diameter of helices,(d),cm in sand for the embedment ratios equal 1, 2, 3, 4, 5, 6 and 7 .It can be noticed that the uplift loads increase with increasing of diameter of helix and the relations can be represents as follows:
$\mathrm{Pu}=0.35 \mathrm{~d}-0.8$ -For $\mathrm{R}=1$
$\mathrm{Pu}=1.03 \mathrm{~d}-2.9$ For $\mathrm{R}=2$
$\mathrm{Pu}=1.60 \mathrm{~d}-3.5$ -For $\mathrm{R}=3$
$\mathrm{Pu}=2.24 \mathrm{~d}-4.7$ -For $\mathrm{R}=4$
$\mathrm{Pu}=3.14 \mathrm{~d}-7.4$ -For $\mathrm{R}=5$
$\mathrm{Pu}=3.86 \mathrm{~d}-8.7$ For $\mathrm{R}=6$
$\mathrm{Pu}=4.67 \mathrm{~d}-10.7$ -For $\mathrm{R}=7$

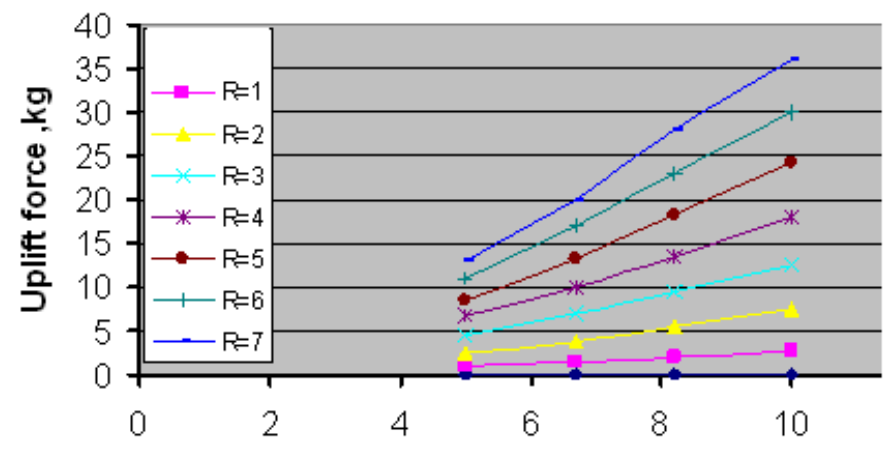

Diameter of helix , cm

Fig. 7. shows the relationships between uplift loads of helical piles in sand soil with the different helical diameters

Figure 8 shows the relationship between the compression and uplift loads of helical piles in sand soil with different helical diameters and various embedment ratios 1, 2, 3, 4, 5, 6 and

Journal of Engineering Sciences, Assiut University, Faculty of Engineering, Vol. 41, No. 6, November, 2013, E-mail address: jes@aun.edu.eg 
Hamdy H.A. Abdel-Rahim et al., The compression and uplift bearing capacities of helical piles in cohesionless soil, pp. 2055 - 2064

7 . The figure shows proportionally increases between the two load values. A straight line can represent the relationship as follows:

\section{Uplift load $=0.06($ Compression load $)-4.065$}

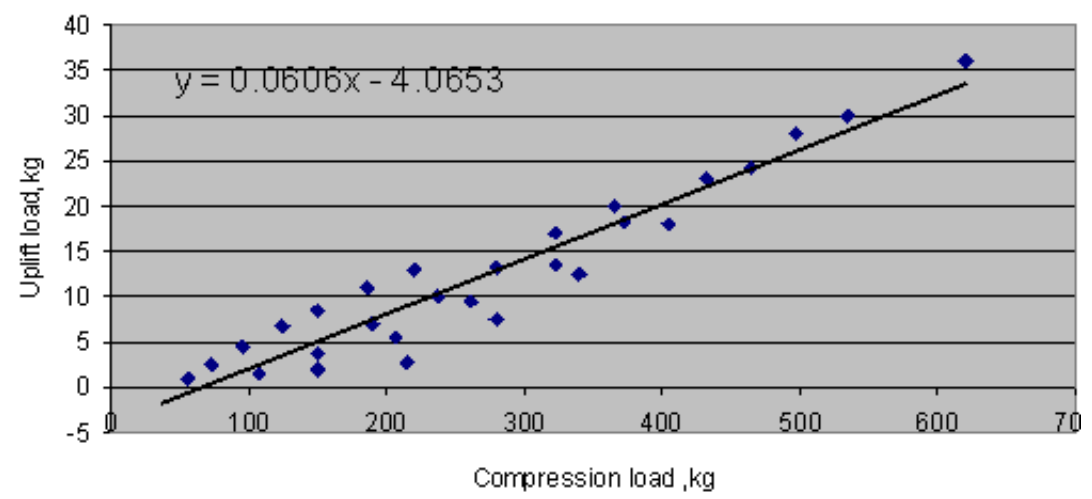

Fig. 8. shows the relations between the compression and uplift loads of helical piles in sand soil with various embedment ratio,D/d

\section{Conclusions}

- The helical pile foundation system is known for its ease and speed of installation. Installation generally requires no soil removal of soil, so there are no spoils to dispose of.

- The designer simply uses soil sand state around the helical plate depending on the compression or uplift load values.

- Helical pile is effective in transporting the compression and pullout loads of construction to the soil.

- The capacity of helical pile increases with increasing the depth of embedment in sand soil and size of helix .

- For any size of helical pile installed in the sand with various embedded depths the relation between compression,Pc and uplift,Pu capacities of helical pile for the studied cases can be represented as follows:

\section{Uplift load = $0.06($ Compression load $)-4.065$}

\section{References}

[1]Little, A.L.(1961):"Foundations, Edward Arnold (publishers) Ltd., Lond- on First Edition.

[2]Wilson, G.(1950):"The bearing capacity of screw piles and screws Crete cylinders, Journal of Institution of Civil Engineering, London, Vol.34, PP.4-37.

[3]Meyerhof, G.G. (1950):"Discussion to paper on the bearing capacity of screw piles and screw Crete cylinders" by Wilson, G., Journal of Institution of Civil Engineering, London, Vol.34, PP.84-86.

[4]Skempton, A.W. (1950):"Discussion to paper on the bearing capacity of screw piles and screwcrete cylinders" by Wilson, G., Journal of Institution of Civil Engineering, London, Vol.34, PP.76-81.

[5]Mitsch, M.P. and Clemence, S.P. (1985):"The uplift capacity of helical anchors in sand, "Uplift Behavior of Anchor Foundations in soil, ASSC, Michigan, USA, PP.26-27.

[6]Ghaly, A.M. and Clemence (1998):"Bearing and Pullout Capacity", Helix Pier Engineering, Hand book 2000,"PP.5-6.

Journal of Engineering Sciences, Assiut University, Faculty of Engineering, Vol. 41, No. 6, November, 2013, E-mail address: jes@aun.edu.eg 
2064

Hamdy H.A. Abdel-Rahim et al., The compression and uplift bearing capacities of helical piles in cohesionless soil, pp. 2055 - 2064

[7]A.B. Chance (1993):" Bearing and Pullout Capacity", Helix Pier Engineering, Hand book 2000,"PP.5-6.

[8]Hot, R.M. and Clemency, SP (1989):"Uplift capacity of helical anchors in soil, "Proceedings 12 Th Int. Conference on Soil Mechanics and Foundation Engineering, Brazil, Vol.2, PP.1019-1022.

[9]Sharif M.A.(2005): "The behaviour of helical pier in sand ,"Journal of engineering sciences, faculty of Eng., Assiut university, vol,33, No. 5, September, PP.1703-1713.

[10]Ghaly, A.M. (1995):"Bearing and Pullout Capacity", Helix Pier Engineering, Hand book 2000,"PP.5-6.

[11]Das, B. M. (1990). Earth Anchon. Elsevier, Amsterdam, 241 p.

[12]Parr, R. G., and Vanner, M. J. (1962). "Strength Tests on Overhead Line Tower Foundations"; Electrical Research Association, Report $0 K 28$.

[13]Mitsch, M.P. and Clemence, S.P. (1985):"The uplift capacity of helical anchors in sand, "Uplift Behavior of Anchor Foundations in soil, ASSC, Michigan, USA, PP.26-27.

[14]Meyrehof, G.G. and Adams, J.I. (1968):"The ultimate uplift capacity of foundation," Canadian Geotechnical Journal, Vol.5, No.4, PP.225-244.

[15]Clemence S. P. and Pepe F. D. (1984). Measurement of Lateral Stress Around Multihelix Anchors in Sand. ASTM Geotechnical Testing Journal, Vol. 7, No 1-4, pp. 145-152.

[16]Ghaly A. and Hanna A. (1994). Ultimate Pullout Resistance of Single Vertical Anchors. Canadian Geotechnical Journal. p.p. 661-671.

[17]Das, B. M. (1 980). "A Procedure for Estimation of Ultimate Uplift Capacity of Foundations in Clayn; Soils and Foundation, Japan, Vol. 20, No. 1, pp. 77-82.

\section{Notations}

$\mathrm{A}=$ surface area of the helix plate, $\mathrm{cm}^{2}$;

$\mathrm{d}=$ helix plate diameter, $\mathrm{cm}$;

$\mathrm{D}=$ embedded depth of helix in sand, $\mathrm{cm}$;

$\mathrm{D} / \mathrm{d}=$ embedment ratio;

$\mathrm{Pc}=$ Bearing capacity (compression load) of helix pile, $\mathrm{kg}$;

$\mathrm{Pu}=$ Bearing capacity (uplift load)of helix pile, $\mathrm{kg}$;

\section{قدرة تحمل الخوازيق الحلزونية للضغط والسحب في الرمل}

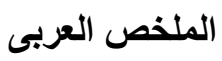

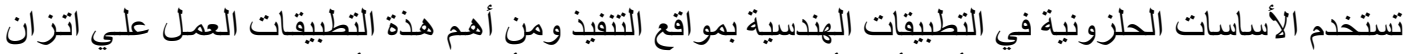

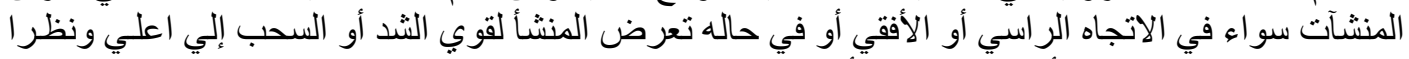

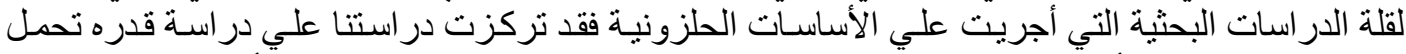

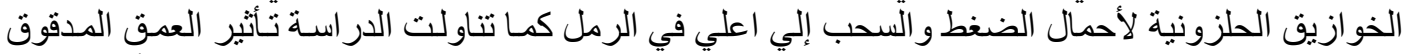

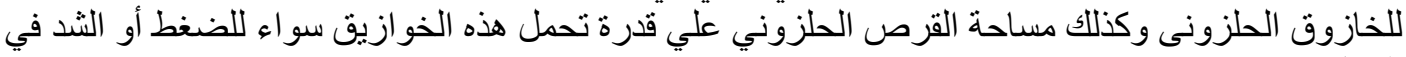
الرمل.

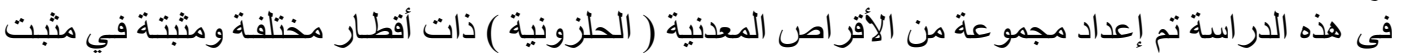

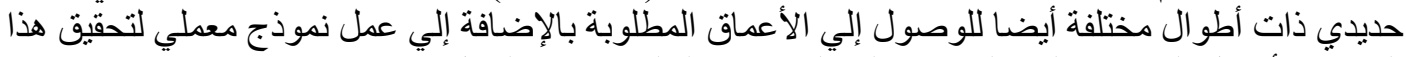

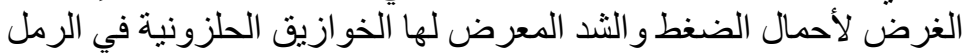

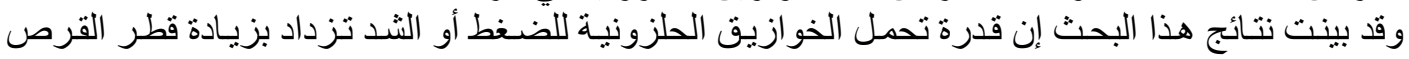

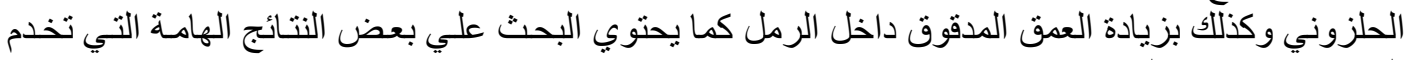
المهندس في موقع التنفيذ.

Journal of Engineering Sciences, Assiut University, Faculty of Engineering, Vol. 41, No. 6, November, 2013, E-mail address: jes@aun.edu.eg 